\title{
Pain-related risk factors after arthroscopic minimally invasive treatment of meniscus injury of knee joints
}

\author{
JIANG XU and FEI BIAN \\ Department of Orthopedics, Quwo County People's Hospital, Linfen, Shanxi 043400, P.R. China
}

Received August 22, 2019; Accepted February 11, 2020

DOI: $10.3892 /$ etm.2020.8953

\begin{abstract}
Pain-related risk factors after arthroscopic minimally invasive treatment of meniscus injury of knee joints were explored. Altogether 42 patients (conservative group), 40 patients (open group) and 46 patients (minimally invasive group) who received conservative treatment or arthroscopic knee surgery at the Quwo County People's Hospital were selected. The clinical effects of patients in the three groups at 24 weeks after treatment were observed. The knee joint activity, the knee injury and osteoarthritis outcome score (KOOS), Lysholm knee joint function score, VAS pain score and WOMAC score were recorded before treatment, at 24 weeks after treatment and at 2 years after treatment. Complications were also recorded. The related risk factors of postoperative pain were analyzed. There was no significant difference between the short-term efficacy of conservative treatment and that of surgical treatment $(\mathrm{P}>0.05)$; however, the long-term improvement effect of the surgical treatment on knee joint function and pain was better $(\mathrm{P}<0.05)$. The short-term and long-term effects of arthroscopic surgery were close to those of the open surgery. Arthroscopic surgery had a good long-term improvement effect on knee joint function and pain $(\mathrm{P}<0.05)$, and the incidence of postoperative pain was low $(\mathrm{P}<0.05)$. The results of logistic multivariate regression analysis manifested that WOMAC score, articular cartilage injury, time of postoperative weight bearing $<1$ week, no postoperative cold compress and open knee surgery were independent risk factors that affected postoperative pain $(\mathrm{P}<0.05)$. In conclusion, arthroscopic minimally invasive treatment has a good effect on patients with meniscus injury of knee joints who fail conservative treatment. Articular cartilage injury, postoperative weight bearing, cold compress and type of operation are independent risk factors that affect postoperative pain. Clinicians should bring patient attention
\end{abstract}

Correspondence to: Dr Jiang $\mathrm{Xu}$, Department of Orthopedics, Quwo County People's Hospital, 3 Fudong Street, Linfen, Shanxi 043400, P.R. China

E-mail: xjqw123@163.com

Key words: arthroscopic minimally invasive treatment, meniscus injury of knee joints, postoperative pain, risk factor to the prevention of meniscus injury and further improve the efficacy of treatment.

\section{Introduction}

Meniscus is an important crescent-shaped structure of the knee joint cavity, which has the functions of transferring load, lubricating joints, distributing stress, stabilizing and coordinating joint movement (1). Meniscus injury of knee joints is a type of muscle system injury that mainly involves degeneration of meniscus morphology (2). The incidence of meniscus injury in a high-load moving crowd is $20-35 \%$ and in elderly patients with osteoporosis is $30-40 \%$ (3). The distribution of meniscus blood vessels is not abundant and the repair potential is limited. Only a small part of a meniscus tear can be repaired. The healing of meniscus is uncertain even under optimal conditions (4). Surgical treatment is necessary.

At present, the commonly used surgical method is meniscus repair surgery in knee joints (5). However, the traditional open new surgery is traumatic and patients are prone to complications, such as joint stiffness and joint adhesion after treatment (6). Due to the continuous development of the minimally invasive amplification technology and the update on the minimally invasive concept, the minimally invasive surgical treatment has been applied to various surgical treatments and has achieved good results (7). In view of the extensive application of arthroscopic meniscus surgery in recent years, more evidence-based practical studies are needed to support meniscus surgery and improve its efficacy. In recent years, systematic research reports have questioned the efficacy of arthroscopic knee surgery for middle-aged and elderly patients with degenerative meniscus tear, with or without knee osteoarthritis $(8,9)$. In addition, patients often suffer from persistent pain after partial or complete meniscectomy. Preventing and reducing the occurrence of postoperative pain is of great significance to the rehabilitation of patients and the improvement of their quality of life.

The present study explored the efficacy of arthroscopic minimally invasive treatment of meniscus injury of knee joints in middle-aged and elderly patients and the risk factors related to postoperative pain, in order to provide reference for the clinical treatment of meniscus injury of knee joints and reduce postoperative pain. 


\section{Patients and methods}

Research subjects. From May 2012 to April 2015, 128 patients with meniscus injury of knee joints, 45-75 year of age, were selected. After the diagnosis of patients, clinicians put forward treatment methods and reached a consensus. Altogether 42 patients received conservative treatment (conservative group), 40 patients received open knee surgery (open group), and 46 patients received arthroscopic knee surgery (minimally invasive group). Inclusion criteria: All patients had obvious meniscus injury symptoms; patients had grade I or II injury, indicated by MRI of chronic injury, or their injury in acute stage was small $(<5 \mathrm{~mm})$ with stable edge longitudinal tear and there was no typical bounce and interlocking clinical symptoms, apart from pain and discomfort of knee joint; patients had unilateral injury; no meniscus tear, anterior cruciate ligament or posterior cruciate ligament reconstruction surgery was performed before treatment; and no pregnant or nursing women were enrolled. Exclusion criteria: Patients with other joint injuries, serious infections, tumor, lower limb fracture within 24 weeks before surgery, bone metabolic diseases, such as osteoporosis, with contraindications to surgery, history of drug allergy, and mental and communication disorders. The study conformed to the Helsinki Declaration, and was approved by the Ethics Committee of the Quwo County People's Hospital (Linfen, China). Patients who participated in this research had complete clinical data. Signed written informed consents were obtained from the patients and/or guardians.

Treatment methods. Conservative treatment: In the acute stage, splint or plaster was applied to fix the knee joint and keep at rest position. During this period, patients were guided to do active contraction exercise of lower limbs to prevent muscle contracture. The fixation was continued for 4-6 weeks. After the fixative was removed, patients were guided to stretch and bend the knee joint and walk following a rehabilitation training program once every other day, $20 \mathrm{~min} /$ time, for 1 month. If necessary, acupuncture and massage were used.

Open knee joint surgery: Patients underwent spinal anesthesia. After anesthesia was accomplished, the skin and subcutaneous tissue were opened, and the joint cavity was exposed; the torn edge was removed with a small curette or scalpel to promote meniscus healing, and the meniscus was sutured. If the meniscus could not be sutured, the meniscus tissue was removed, the wound was cleaned, and the surgical incision was closed after there was no residue.

Arthroscopic knee surgery: Patients were anesthetized with spinal anesthesia. After anesthesia was accomplished, transverse incisions of $0.5 \mathrm{~cm}$ were made on both sides of the knee infrapatellar ligament at the approach points and the suprapatellar bursa of the knee was inflated with $300 \mathrm{ml}$ of normal saline. The arthroscope was inserted through the infrapatellar medial-lateral incision, and the meniscus was excised after the specific damage was confirmed. The damaged meniscus was repaired with blue forceps, the hyperplastic synovium in the joint was cleaned with planer and plasma knife, the debris was cleaned with negative pressure suction, and the meniscus was sutured and partially or completely removed when necessary. The wound was cleaned up, the surgical incision was closed after there was no residue and the wound was bound up under pressure for 1 day. On the next day after surgery, patients were instructed to get out of bed and stand up. Generally, patients could get out of bed and move after 3 days and a proper amount of straight leg-raising exercises and knee-bending exercises were carried out in order to restore the function of knee tissue.

Observation indicators. The clinical effects of patients in the three groups at 24 weeks after treatment were observed. Knee joint activity, knee injury and osteoarthritis outcome score (KOOS), Lysholm knee joint function score, VAS pain score and WOMAC score were recorded before treatment, at 24 weeks after treatment and at 2 years after treatment. The complications that occurred within 2 years were also recorded. The related risk factors of postoperative pain were analyzed.

Efficacy evaluation: Markedly effective: After treatment, symptoms such as knee joint pain and swelling disappeared, knee joint function basically returned to normal, and normal life could be achieved. Effective: After treatment, symptoms such as knee joint pain and swelling were obviously improved, and the limitation of knee joint function and activity was obviously relieved. Ineffective: After treatment, symptoms such as knee joint pain and swelling had no obvious change, and knee joint function and activity were limited.

Statistical analysis. SPSS 19.0 software (AsiaAnalytics; formerly SPSS China) was used for statistical analysis. The measurement data were expressed as percentages (\%) and $\chi^{2}$ test was used for the comparison of rates. The counting data were expressed as the mean $\pm \mathrm{SD}$. Comparison between the two groups was made using t-test, between multiple groups was made using analysis of variance (ANOVA), and comparison of data at different time points in the same group was made using repeated measures ANOVA. The post hoc test employed was LSD test. Postoperative pain-related risk factors were analyzed by logistic regression analysis. $\mathrm{P}<0.05$ was considered to indicate a statistically significant difference.

\section{Results}

General data. There were 42 patients in the conservative group, including 29 male patients and 13 female patients, $55.93 \pm 9.75$ years of age; there were 40 patients in the open group, including 28 male patients and 12 female patients, $54.33 \pm 8.09$ years of age; and there were 46 patients in the minimally invasive group, including 35 male patients and 11 female patients, $54.39 \pm 8.27$ years of age. According to the results, there was no significant difference among the three groups $(\mathrm{P}>0.05)$ in sex, age, body mass index (BMI), course of the disease and other factors presented in Table I $(\mathrm{P}>0.05)$.

Clinical efficacy. At 24 weeks after treatment, there were 10 markedly effective cases, 17 effective cases and 15 ineffective cases in the conservative group; there were 16 markedly effective cases, 17 effective cases and 7 ineffective cases in the open group; and there were 22 markedly effective cases, 16 effective cases and 8 ineffective cases in the minimally invasive group. According to the results, there was no significant difference in efficacy among the three groups $(\mathrm{P}>0.05$; Table II). 
Table I. Patient general characteristics.

\begin{tabular}{|c|c|c|c|c|c|}
\hline Characteristics & $\begin{array}{l}\text { Conservative } \\
\text { group }(n=42)\end{array}$ & $\begin{array}{l}\text { Open group } \\
\quad(n=40)\end{array}$ & $\begin{array}{l}\text { Minimally invasive } \\
\text { group }(n=46)\end{array}$ & $\chi^{2} / F$ & P-value \\
\hline $\operatorname{Sex}(n, \%)$ & & & & 0.639 & 0.726 \\
\hline Male & $29(69.05)$ & $28(70.00)$ & $35(76.09)$ & & \\
\hline Female & $13(30.95)$ & $12(30.00)$ & $11(23.91)$ & & \\
\hline Age (years) & $55.93 \pm 9.75$ & $54.33 \pm 8.09$ & $54.39 \pm 8.27$ & 0.456 & 0.635 \\
\hline BMI $\left(\mathrm{kg} / \mathrm{m}^{2}\right)$ & $21.96 \pm 2.63$ & $22.14 \pm 2.05$ & $22.32 \pm 2.54$ & 0.057 & 0.945 \\
\hline Course of disease (months) & $5.62 \pm 0.28$ & $5.58 \pm 0.35$ & $5.66 \pm 0.46$ & 0.489 & 0.614 \\
\hline Type of meniscus injury $(\mathrm{n}, \%)$ & & & & 11.185 & 0.083 \\
\hline Degenerative injury & $8(19.05)$ & $5(12.50)$ & $7(15.22)$ & & \\
\hline Simple horizontal tear & $13(30.95)$ & $7(17.50)$ & $7(15.22)$ & & \\
\hline Complex horizontal tear & $4(9.52)$ & $14(35.00)$ & $17(36.96)$ & & \\
\hline Longitudinal tear of meniscus & $17(40.48)$ & $14(35.00)$ & $15(32.61)$ & & \\
\hline WOMAC index & $110.77 \pm 6.10$ & $108.97 \pm 10.07$ & $113.33 \pm 8.92$ & 2.861 & 0.061 \\
\hline Knee joint (n, \%) & & & & 0.065 & 0.968 \\
\hline Left & $19(45.24)$ & $17(42.50)$ & $20(43.48)$ & & \\
\hline Right & $23(54.76)$ & $23(57.50)$ & $26(56.52)$ & & \\
\hline MRI grading $(\mathrm{n}, \%)$ & & & & 0.136 & 0.943 \\
\hline I & $24(57.14)$ & $24(60.00)$ & $28(60.87)$ & & \\
\hline II & $18(42.86)$ & $16(40.00)$ & $18(39.13)$ & & \\
\hline Articular cartilage injury $(\mathrm{n}, \%)$ & & & & 0.762 & 0.683 \\
\hline Yes & $7(16.67)$ & $9(22.50)$ & $11(23.91)$ & & \\
\hline No & $35(83.33)$ & $31(77.50)$ & $35(76.09)$ & & \\
\hline Meniscectomy (n, \%) & & & & 1.329 & 0.249 \\
\hline Yes & & $31(77.50)$ & $40(86.96)$ & & \\
\hline No & & $9(22.50)$ & $6(13.04)$ & & \\
\hline Postoperative weight bearing (n, \%) & & & & 0.870 & 0.647 \\
\hline$<1$ week & $6(14.29)$ & $8(20.00)$ & $6(13.04)$ & & \\
\hline$\geq 1$ week & $36(85.71)$ & $32(80.00)$ & $40(86.96)$ & & \\
\hline Cold compress after surgery $(\mathrm{n}, \%)$ & & & & 0.923 & 0.309 \\
\hline Yes & $29(69.05)$ & $30(75.00)$ & $36(78.26)$ & & \\
\hline No & $13(30.95)$ & $10(25.00)$ & $10(21.74)$ & & \\
\hline
\end{tabular}

BMI, body mass index.

Table II. Clinical efficacy $(n, \%)$.

\begin{tabular}{lccrr}
\hline Efficacy & $\begin{array}{c}\text { Conservative } \\
\text { group }(\mathrm{n}=42)\end{array}$ & $\begin{array}{c}\text { Open group } \\
(\mathrm{n}=40)\end{array}$ & $\begin{array}{c}\text { Minimally invasive } \\
\text { group (n=46) }\end{array}$ & $\chi^{2}$ \\
\hline Markedly effective & $10(23.81)$ & $16(40.00)$ & $22(47.83)$ & 5.558 \\
Effective & $17(40.48)$ & $17(42.50)$ & $16(34.78)$ & 0.062 \\
Ineffective & $15(37.71)$ & $7(17.50)$ & $8(17.39)$ & 0.588 \\
\hline
\end{tabular}

The treatment lasted 24 weeks.

Knee joint activity. There was no significant difference in knee joint activity among the three groups before treatment or at 24 weeks after treatment $(\mathrm{P}>0.05)$. The knee joint activity of the three groups at 24 weeks after treatment and at 2 years after treatment was higher than that before treatment $(\mathrm{P}<0.05)$. There was no significant difference between the knee joint activity at 2 years after treatment and at 24 weeks after treatment $(\mathrm{P}>0.05)$. The results of the intergroup comparison 
showed that there was no significant difference in knee joint activity between the open group and the minimally invasive group at 2 years after treatment $(\mathrm{P}>0.05)$; however, both were higher than that in the conservative group $(\mathrm{P}<0.05 ;$ Fig. 1$)$.

KOOS score. Before treatment, at 24 weeks after treatment and at 2 years after treatment, there was no significant difference in the KOOS score among the three groups $(\mathrm{P}>0.05)$. There was no significant difference between the KOOS scores at 24 weeks after treatment and at 2 years after treatment $(\mathrm{P}>0.05)$; however, KOOS score was higher at both time points than that before treatment $(\mathrm{P}<0.05$; Fig. 2).

Lysholm score. There was no significant difference in the Lysholm score among the three groups before treatment or at 24 weeks after treatment ( $>>0.05)$. Lysholm score in the three groups at 24 weeks after treatment and at 2 years after treatment was higher than that before treatment $(\mathrm{P}<0.05)$, and the score at 2 years after treatment was higher than that at 24 weeks after treatment $(\mathrm{P}<0.05)$. The results of the intergroup comparison showed that the Lysholm score of patients in the minimally invasive group was higher than that in the open group $(\mathrm{P}<0.05)$ at 24 weeks and 2 years after treatment, and in the open group was higher than that in the conservative group $(\mathrm{P}<0.05)$ at 2 years after treatment (Fig. 3).

VAS score. The VAS score of patients in the three groups before treatment showed no significant difference $(\mathrm{P}>0.05)$. The VAS score of patients in the three groups at 24 weeks after treatment and at 2 years after treatment were lower than that before treatment $(\mathrm{P}<0.05)$; however, the VAS score of patients in the three groups at 2 years after treatment were higher than that at 24 weeks after treatment $(\mathrm{P}<0.05)$. The results of the intergroup comparison revealed that the VAS score of patients in the minimally invasive group was lower than that in the open group at 24 weeks and 2 years after treatment $(\mathrm{P}<0.05)$, whereas that in the open group was lower than that in the conservative group $(\mathrm{P}<0.05$; Fig. 4).

WOMAC score. There was no significant difference in the WOMAC score among the three groups before treatment $(\mathrm{P}>0.05)$. At 24 weeks and 2 years after treatment, the WOMAC scores of patients in the three groups were lower than those before treatment $(\mathrm{P}<0.05)$; however, at 2 years after treatment, the WOMAC scores of patients in the three groups were higher than those at 24 weeks after treatment $(\mathrm{P}<0.05)$. Intergroup comparison between groups showed that the WOMAC scores of patients at 24 weeks and 2 years after treatment in the minimally invasive group were lower than those in the open group $(\mathrm{P}<0.05)$ and those of the open group were lower than those in the conservative group $(\mathrm{P}<0.05$; Fig. 5).

Postoperative pain. Both the open group and the minimally invasive group achieved primary healing of the surgical incision after surgery; no obvious complications, such as lower limb venous thrombosis and incision infection occurred, and no obvious adverse reactions occurred in the conservative group. The incidence of postoperative pain was $52.5 \%$ ( 21 cases) in the open group and $26.09 \%$ (12 cases) in the minimally invasive group, which was lower than that in the open group $(\mathrm{P}=0.012)$.

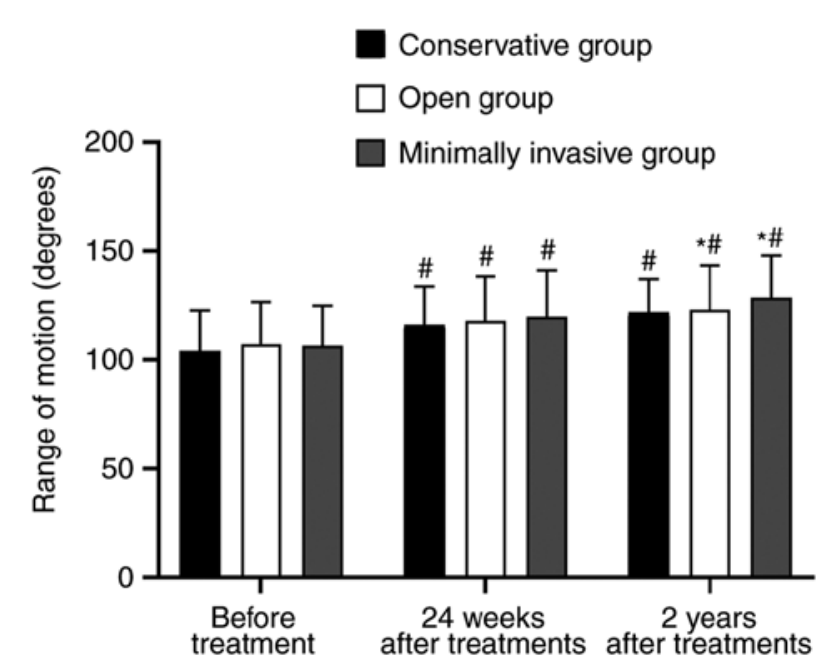

Figure 1. Analysis of knee joint activity before and after treatment of patients in the three groups. ${ }^{*} \mathrm{P}<0.05$, compared with the conservative group at the same time point; ${ }^{\#} \mathrm{P}<0.05$, compared with the same group before treatment.

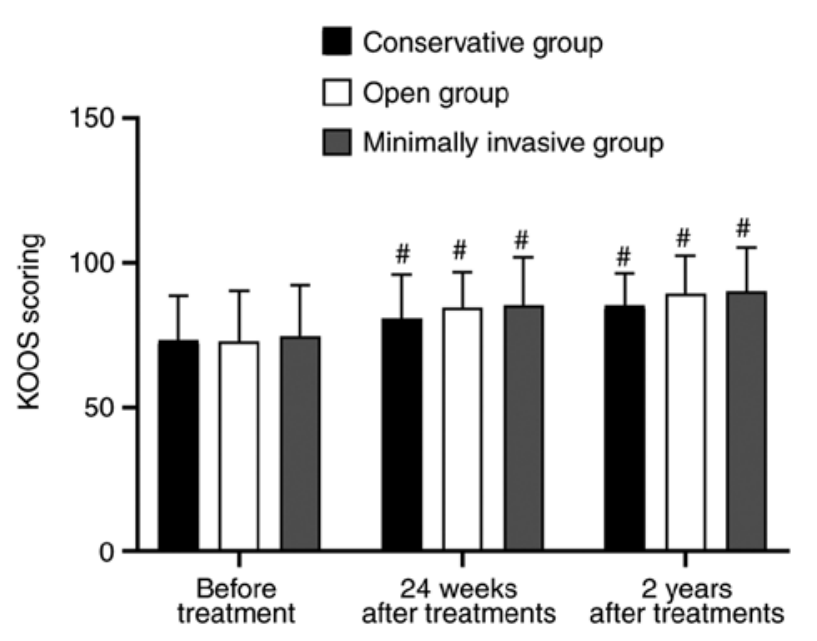

Figure 2. KOOS score analysis of patients in the three groups before and after treatment. " $\mathrm{P}<0.05$, compared with the same group before treatment. KOOS, knee injury and osteoarthritis outcome score.

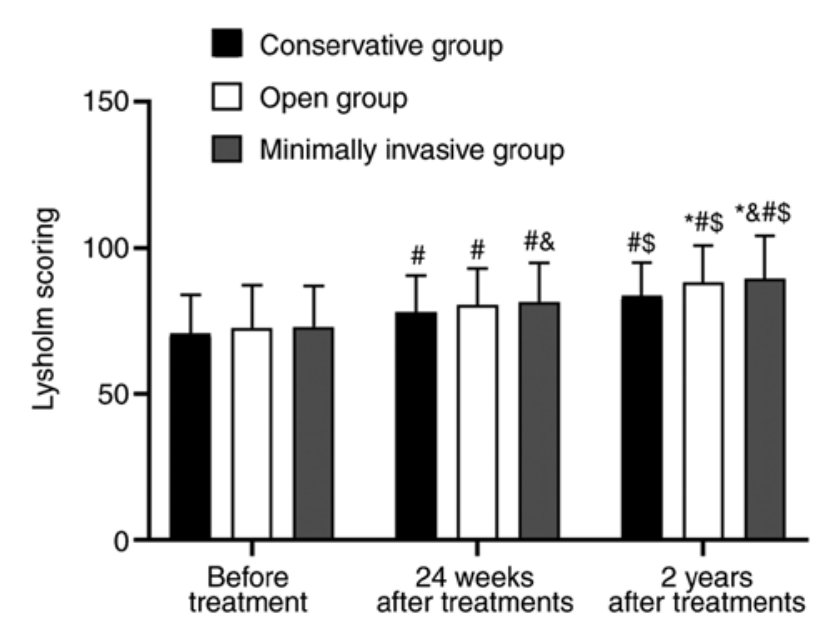

Figure 3. Lysholm scores of patients in the three groups. ${ }^{*} \mathrm{P}<0.05$, compared with the conservative group at the same time point; ${ }^{\&} \mathrm{P}<0.05$, compared with the open group at the same time point; ${ }^{\#} \mathrm{P}<0.05$, compared with the same group before treatment; and ${ }^{\$} \mathrm{P}<0.05$, compared with the same group at 24 weeks after treatment. 


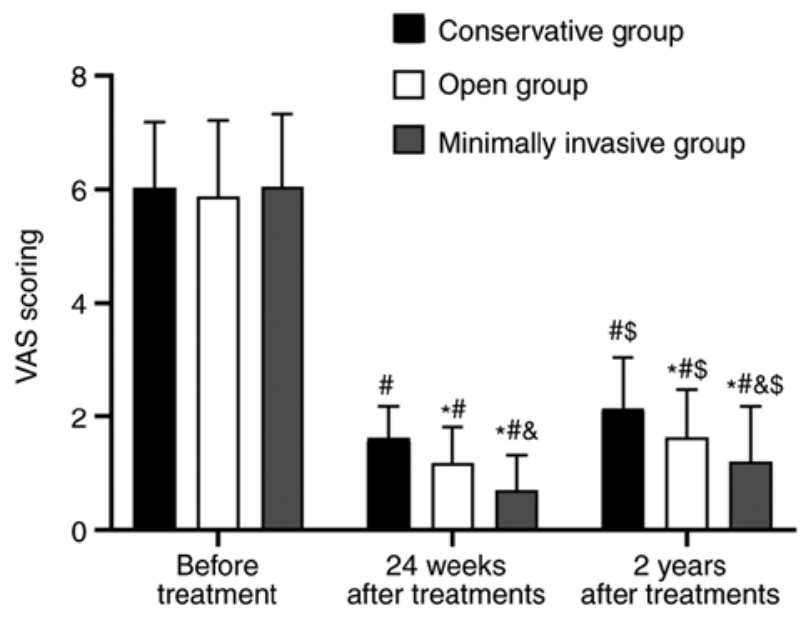

Figure 4 . VAS scores of patients in the three groups. "P<0.05, compared with the conservative group at the same time point; ${ }^{\text {}} \mathrm{P}<0.05$, compared with the open group at the same time point; ${ }^{\prime} \mathrm{P}<0.05$, compared with the same group before treatment; and ${ }^{\$} \mathrm{P}<0.05$, compared with the same group at 24 weeks after treatment.

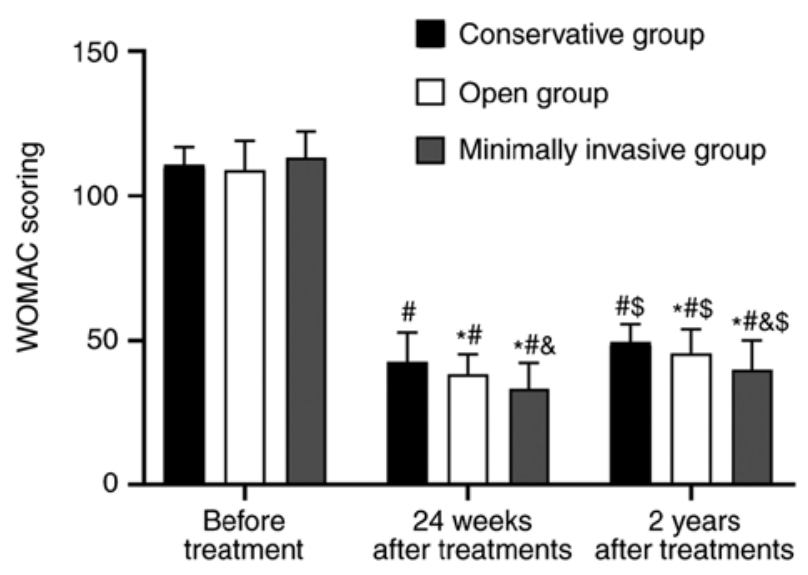

Figure 5. WOMAC scores of patients in the three groups. ${ }^{*} \mathrm{P}<0.05$, compared with the conservative group at the same time point; ${ }^{\circledR} \mathrm{P}<0.05$, compared with the open group at the same time point; ${ }^{\prime \prime} \mathrm{P}<0.05$, compared with the same group before treatment; and ${ }^{\$} \mathrm{P}<0.05$, compared with the same group at 24 weeks after treatment.

Analysis of risk factors for postoperative pain. The patients were divided into the pain group and the painless group according to whether postoperative pain occurred. Univariate analysis of postoperative pain showed that the type of meniscus injury, WOMAC score, articular cartilage injury, time of postoperative weight bearing $<1$ week, no postoperative cold compress and open knee joint surgery are risk factors affecting postoperative pain (Table III). These factors were used to establish the logistic multivariate analysis model, and it was revealed that WOMAC score, articular cartilage injury, time of postoperative weight bearing $<1$ week, no postoperative cold compress and open knee joint surgery are independent risk factors causing postoperative pain (Tables III and IV).

\section{Discussion}

Meniscus injury of knee joints is one of the most common joint diseases and one of the important causes of osteoarthritis $(10,11)$. Repair or resection of meniscus through surgery is the most frequent means of meniscus injury treatment (12). Some studies have reported that there is no significant difference between conservative and surgical treatment after 1 year $(13,14)$. Therefore, in the present study the efficacy of conservative and surgical treatment in meniscus injury were compared, the application value of the minimally invasive treatment in meniscus injury surgical treatment was further analyzed and the risk factors affecting postoperative pain were investigated in order to improve the effectiveness of surgical treatment.

The results of the present study revealed that there was no significant difference between the short-term efficacy ( 24 weeks after treatment) of the surgical treatment and that of the conservative treatment, and there was no significant difference in the improvement degree of KOOS, Lysholm, VAS and WOMAC scores. The analysis of the long-term efficacy results (2 years after treatment) manifested that the improvement of KOOS, Lysholm and WOMAC scores of the patients who received surgical treatment was better than that of the conservative treatment. The reason might be that some patients had meniscus tear caused by knee joint degeneration, cartilage damage, or synovitis. In addition, the patients included in the present study were older and the healing potential of meniscus was further reduced, so the long-term efficacy of conservative treatment was lower than that of the surgical treatment. Moreover, pain was an important criterion for evaluating the efficacy in this study. Surgical treatment presented more advantages in improving the pain caused by meniscus injury (15), which also suggests that the long-term efficacy of surgical treatment was improved. However, the VAS score of patients treated conservatively and those treated surgically was significantly increased after 2 years, suggesting that the condition of patients might get worse. Thus, further investigation is needed to determine the relevant causes, which will be the aim of our future research. Sihvonen et al (16) reported that after 1 year of treatment, the efficacy of operation on patients with osteoarthritis in meniscus tear had no difference compared with that of the sham operation. Herrlin et al (17) and Katz et al (18) also verified that, during short-term and medium-term follow-up, the operation treatment of patients did not show sufficient advantages compared with non-operation treatments, such as exercise therapy. Therefore, combined with these aforementioned conclusions, the conservative treatment is still preferred for patients with meniscus injury of knee joints.

However, $30 \%$ of patients receiving conservative treatment have failed treatment, and the conversion rate from non-surgical to surgical treatment ranges from 0 to $35 \%$ (19). The efficacy of open surgery and arthroscopic minimally invasive surgery in meniscus injury was analyzed in the present study. The short-term and long-term effects of the two methods were similar. The improvement of Lysholm, VAS and WOMAC scores of patients who received arthroscopic surgery was better than that of the open surgery after 2 years of treatment, and the incidence of postoperative pain in open surgery was significantly higher than that of arthroscopic surgery. Therefore, overall analysis showed that arthroscopic surgery was better than open surgery. In a report of meniscus implantation, the radial displacement of the bone graft tunnel internal fixation pad under arthroscopy was significantly 
Table III. Univariate analysis of postoperative pain.

\begin{tabular}{|c|c|c|c|c|}
\hline Variables & Pain $(n=33)$ & Painless $(n=53)$ & $\chi^{2} / \mathrm{t}$ & P-value \\
\hline $\operatorname{Sex}(\mathrm{n}, \%)$ & & & 0.171 & 0.679 \\
\hline Male & $25(75.76)$ & $38(71.70)$ & & \\
\hline Female & $8(24.24)$ & $15(28.30)$ & & \\
\hline Age $(n, \%)$ & & & 2.153 & 0.142 \\
\hline$<60$ years & $8(24.24)$ & $21(39.62)$ & & \\
\hline$\geq 60$ years & $25(75.76)$ & $32(60.38)$ & & \\
\hline BMI & $22.32 \pm 1.64$ & $22.17 \pm 1.26$ & 0.634 & 0.477 \\
\hline Type of meniscus injury (n, \%) & & & 12.156 & 0.007 \\
\hline Degenerative degeneration injury & $10(30.30)$ & $2(3.77)$ & & \\
\hline Simple horizontal tear & $4(12.12)$ & $10(18.87)$ & & \\
\hline Complex horizontal tear & $9(27.27)$ & $22(41.51)$ & & \\
\hline Longitudinal tear of meniscus & $10(30.30)$ & $19(35.85)$ & & \\
\hline WOMAC score & $46.72 \pm 8.15$ & $39.02 \pm 9.43$ & 4.555 & $<0.001$ \\
\hline Knee joint (n, \%) & & & 0.652 & 0.420 \\
\hline Left & $16(48.48)$ & $21(39.62)$ & & \\
\hline Right & $17(51.52)$ & $32(60.38)$ & & \\
\hline MRI grading $(\mathrm{n}, \%)$ & & & 0.861 & 0.353 \\
\hline I & $22(66.67)$ & $30(56.6)$ & & \\
\hline II & $11(33.33)$ & $23(43.4)$ & & \\
\hline Articular cartilage injury (n, \%) & & & 7.814 & 0.005 \\
\hline Yes & $13(39.39)$ & $7(13.21)$ & & \\
\hline No & $20(60.61)$ & $46(86.79)$ & & \\
\hline Meniscectomy (n, \%) & & & 1.720 & 0.190 \\
\hline Yes & $25(75.76)$ & $46(86.79)$ & & \\
\hline No & $8(24.24)$ & $7(13.21)$ & & \\
\hline Postoperative weight bearing (n, \%) & & & 7.727 & 0.005 \\
\hline$<1$ week & $10(30.30)$ & $4(7.55)$ & & \\
\hline$\geq 1$ week & $23(69.70)$ & $49(92.45)$ & & \\
\hline Cold compress after surgery $(\mathrm{n}, \%)$ & & & 41.855 & $<0.001$ \\
\hline Yes & $13(39.39)$ & $53(100.00)$ & & \\
\hline No & $20(60.61)$ & $0(0.00)$ & & \\
\hline Type of operation $(n, \%)$ & & & 6.312 & 0.012 \\
\hline Open & $21(63.64)$ & $19(35.85)$ & & \\
\hline Minimally invasive & $12(36.36)$ & $34(64.15)$ & & \\
\hline
\end{tabular}

BMI, body mass index.

Table IV. Multivariate analysis.

\begin{tabular}{lcccccccc}
\hline & & & & & & & & \multicolumn{2}{c}{$95 \% \mathrm{Cl}$} \\
\cline { 3 - 7 } Variables & B & S.E. & Wals & df & Sig. & Exp (B) & Upper limit & Lower limit \\
\hline Type of meniscus injury & 1.696 & 0.785 & 2.447 & 1 & 0.132 & 1.469 & 0.048 & 1.542 \\
WOMAC score & -6.072 & 1.825 & 6.438 & 1 & 0.015 & 3.125 & 1.446 & 5.738 \\
Articular cartilage injury & -1.932 & 1.243 & 4.454 & 1 & 0.035 & 4.523 & 2.224 & 9.687 \\
Postoperative loading & -1.065 & 1.276 & 4.764 & 1 & 0.031 & 3.152 & 1.481 & 8.637 \\
Cold compress after surgery & 1.749 & 1.518 & 4.972 & 1 & 0.022 & 8.269 & 2.637 & 17.428 \\
Operative methods & -1.546 & 1.075 & 3.458 & 1 & 0.041 & 5.754 & 1.973 & 12.565 \\
\hline
\end{tabular}


smaller than that of the open soft tissue internal fixation pad (20). Gu et al (21) also claimed that arthroscopic surgery for diffuse pigmented villonodular synovitis of knee joints had the advantages of short operation time, short hospital stay, less bleeding, high IKDC score and Lysholm score after surgery. These studies suggested that arthroscopy was more advantageous than open surgery in knee joint surgery. Therefore, arthroscopic minimally invasive surgery can be given priority to patients with meniscus injury who need surgical treatment after the failure of a conservative treatment.

The risk factors of postoperative pain in patients were analyzed. Logistic regression analysis indicated that WOMAC score, articular cartilage injury, time of postoperative weight bearing $<1$ week, no postoperative cold compress and open knee surgery were independent risk factors affecting postoperative pain. Degenerative meniscus injury is more common in the elderly patients, who often suffer from different degrees of osteoarthritis, and residual osteoarthritis is the vital pain-related risk factor (22). Some research reports on knee joint injury have shown that the occurrence of cartilage injury is related to the increase of pain frequency after anterior and posterior ligament reconstruction $(23,24)$. In addition, patients with higher BMI and women are more prone to pain after anterior and posterior ligament reconstruction (25). The similarities and differences of these results suggest that our research has some limitations, such as the small sample size, the wide age range of patients, and the fact that the meniscus repair and meniscectomy were not studied in depth. Thus, further research is needed. In some severe trauma cases, meniscus, cruciate ligament and lateral collateral ligament can be injured at the same time. In these cases, it can not be determined whether the pain is caused by meniscus injury. Therefore, our results and conclusions need more research and further verification.

In conclusion, arthroscopic minimally invasive treatment has a good effect on patients with meniscus injury of knee joints who fail conservative treatment. Articular cartilage injury, postoperative weight bearing, cold compress and type of operation are independent risk factors that affect postoperative pain. Clinicians should bring patient attention to the prevention of meniscus injury and further improve the efficacy of treatment.

\section{Acknowledgements}

Not applicable.

\section{Funding}

No funding was received.

\section{Availability of data and materials}

The datasets used and/or analyzed during the present study are available from the corresponding author on reasonable request.

\section{Authors' contributions}

JX wrote the manuscript, performed the arthroscopic knee surgery, and interpreted and analyzed the patient data. FB designed the study, was responsible for the conservative treatment of the patients, performed the open knee surgery and was responsible for the analysis and discussion of the data. Both authors read and approved the final version of the manuscript.

\section{Ethics approval and consent to participate}

The study was approved by the Ethics Committee of the Quwo County People's Hospital (Linfen, China). Patients who participated in this research had complete clinical data. Signed written informed consents were obtained from the patients and/or guardians.

\section{Patient consent for publication}

Not applicable.

\section{Competing interests}

The authors declare that they have no competing interests.

\section{References}

1. Naimark MB, Kegel G, O'Donnell T, Lavigne S, Heveran C and Crawford DC: Knee function assessment in patients with meniscus injury: A preliminary study of reproducibility, response to treatment, and correlation with patient-reported questionnaire outcomes. Orthop J Sports Med 2: 2325967114550987, 2014.

2. Ebrahimi N, Jalaie S, Salsabili N, Ansari NN and Naghdi S: Knee injury and osteoarthritis outcome score in patients with isolated meniscus injury; validity and reliability. J Res Med Sci 22: 55, 2017.

3. Matsukura Y, Muneta T, Tsuji K, Koga H and Sekiya I: Mesenchymal stem cells in synovial fluid increase after meniscus injury. Orthop Relat Res 472: 1357-1364, 2014.

4. Rai MF and McNulty AL: Meniscus beyond mechanics: Using biology to advance our understanding of meniscus injury and treatment. Connect Tissue Res 58: 221-224, 2017.

5. Brophy RH, Gefen AM, Matava MJ, Wright RW and Smith MV: Understanding of meniscus injury and expectations of meniscus surgery in patients presenting for orthopaedic care. Arthroscopy 31: 2295-2300.e5, 2015.

6. Salzler MJ, Lin A, Miller CD, Herold S, Irrgang JJ and Harner CD: Complications after arthroscopic knee surgery. Am J Sports Med 42: 292-296, 2014.

7. Norton MJ and Ischy ND: Apparatus and method for minimally invasive surgery. US Patent 9,820,771(P). Filed on March 3, 2006; issued November 21, 2017.

8. Khan M, Evaniew N, Bedi A, Ayeni OR and Bhandari M: Arthroscopic surgery for degenerative tears of the meniscus: A systematic review and meta-analysis. CMAJ 186: 1057-1064, 2014.

9. Thorlund JB, Juhl CB, Roos EM and Lohmander LS: Arthroscopic surgery for degenerative knee: Systematic review and meta-analysis of benefits and harms. BMJ 350: h2747, 2015.

10. Meckes JK, Caramés B, Olmer M, Kiosses WB, Grogan SP, Lotz MK and D'Lima DD: Compromised autophagy precedes meniscus degeneration and cartilage damage in mice. Osteoarthritis Cartilage 25: 1880-1889, 2017.

11. Kloefkorn HE, Jacobs BY, Loye AM and Allen KD: Spatiotemporal gait compensations following medial collateral ligament and medial meniscus injury in the rat: Correlating gait patterns to joint damage. Arthritis Res Ther 17: 287, 2015.

12. Vaquero-Picado A and Rodríguez-Merchán EC: Arthroscopic repair of the meniscus: Surgical management and clinical outcomes. EFORT Open Rev 3: 584-594, 2018.

13. Howell R, Kumar NS, Patel N and Tom J: Degenerative meniscus: Pathogenesis, diagnosis, and treatment options. World J Orthop 5: 597-602, 2014.

14. Krause M, Freudenthaler F, Frosch KH, Achtnich A, Petersen W and Akoto R: Operative versus conservative treatment of anterior cruciate ligament rupture. Dtsch Arztebl Int 115: 855-862, 2018. 
15. Filbay SR, Andersson C, Ardern C, Gauffin H and Kvist J: Patient-reported outcome 32 to 37 years following surgically treated or non-surgically treated acute anterior cruciate ligament injury. Osteoarthritis Cartilage 26 (Suppl 1): S52-S53, 2018.

16. Sihvonen R, Paavola M, Malmivaara A, Itälä A, Joukainen A, Nurmi H, Kalske $\mathbf{J}$ and Järvinen TL; Finnish degenerative meniscal lesion study (FIDELITY) group: Arthroscopic partial meniscectomy versus sham surgery for a degenerative meniscal tear. N Engl J Med 369: 2515-2524, 2013.

17. Herrlin SV, Wange PO, Lapidus G, Hållander M, Werner S and Weidenhielm L: Is arthroscopic surgery beneficial in treating non-traumatic, degenerative medial meniscal tears? A five year follow-up. Knee Surg Sports Traumatol Arthrosc 21: 358-364, 2013

18. Katz JN, Brophy RH, Chaisson CE, de Chaves L, Cole BJ, Dahm DL, Donnell-Fink LA, Guermazi A, Haas AK, Jones MH, et al: Surgery versus physical therapy for a meniscal tear and osteoarthritis. N Engl J Med 368: 1675-1684, 2013.

19. Beaufils P, Becker R, Kopf S, Matthieu O and Pujol N: The knee meniscus: Management of traumatic tears and degenerative lesions. EFORT Open Rev 2: 195-203, 2017.

20. De Coninck T, Huysse W, Verdonk R, Verstraete $\mathrm{K}$ and Verdonk P: Open versus arthroscopic meniscus allograft transplantation: Magnetic resonance imaging study of meniscal radial displacement. Arthroscopy 29: 514-521, 2013.
21. Gu HF, Zhang SJ, Zhao C, Chen Y and Bi Q: A comparison of open and arthroscopic surgery for treatment of diffuse pigmented villonodular synovitis of the knee. Knee Surg Sports Traumatol Arthrosc 22: 2830-2836, 2014.

22. Davis TR, Brady O and Dias JJ: Excision of the trapezium for osteoarthritis of the trapeziometacarpal joint: A study of the benefit of ligament reconstruction or tendon interposition. J Hand Surg Am 29: 1069-1077, 2004.

23. Fok AW and Yau WP: Delay in ACL reconstruction is associated with more severe and painful meniscal and chondral injuries. Knee Surg Sports Traumatol Arthrosc 21: 928-933, 2013.

24. Eckstein F, Cotofana S, Wirth W, Nevitt M, John MR, Dreher D and Frobell BR: Greater rates of cartilage loss in painful knees than in pain-free knees after adjustment for radiographic disease stage Data from the Osteoarthritis Initiative. Arthritis Rheumatol 63: 2257-2267, 2011.

25. Dunn WR, Spindler KP, Amendola A, Andrish JT, Kaeding CC, Marx RG, McCarty EC, Parker RD, Harrell FE Jr and An AQ: Which preoperative factors, including bone bruise, are associated with knee pain/symptoms at index anterior cruciate ligament reconstruction (ACLR)? A Multicenter Orthopaedic Outcomes Network (MOON) ACLR Cohort Study. Am J Sports Med 38: 1778-1787, 2010. 